\title{
Assessment of the thermoelectric conversion potential of low-temperature waste heat from textile dry- cleaning processes
}

\author{
Daniele Fiaschi $^{1^{*}}$, Lorenzo Talluri ${ }^{1}$ \\ ${ }^{1}$ Dipartimento di Ingegneria Industriale - Università di Firenze. V. Morgagni 40-44, 50134, FI, Italia
}

\begin{abstract}
Even though textile industry is not considered an energy intensive sector, it comprises a large number of plants consuming and wasting a significant amount of energy that could be, at least partially, conveniently recovered. The objective of this work is to assess the possibilities and convenience of energy recovery from waste heat of different processes of a dry industrial textile laundry.

The various thermal wastes from the processes were identified and characterised, in order to estimate their potential recovery and conversion into electricity.

A suitable system layout was conceived, in order to exploit the heat deriving from thermal waste of different machinery in the factory, having distinct temperature levels, to an ORC powerplant, which converts the recovered heat into electricity.

The ORC cycle was optimized to maximize the thermoelectric efficiency, comparing different possible working fluids. The best fluid was RC318, from which $92.5 \mathrm{~kW}$ power output was achieved, at $9.2 \%$ efficiency.

The economic analysis revealed, conservatively, a payback period of 7 years for the whole system, which is potentially very interesting. The amount of electricity produced by the waste heat recovery equipment is well matched to the company's electrical needs, resulting in a significant reduction of electricity consumption, greatly reducing the electrical withdrawal from the grid and the related costs.

The case study, the proposed solutions and the methodology have general aspects and may be extended to a wide range of cases in the sector of industrial textile laundry.
\end{abstract}

\section{Introduction}

Energy is one of the main costs in textile industry. However, there are several margins of waste energy recovery in textile plants, many of which are even cost effective, thus conveniently applicable. Hasanbeigi and Price [1] analysed 184 energy efficiency measures applicable to textile industry in worldwide case studies, investigated spun yarn spinning and weaving process, wet-processing and fibre production. Rakib et al. [2] addressed very appealing payback time of investments from waste heat recovery in textile industry systems, ranging from less than 1 to 3.5 years. The interesting energy recovery potential from stenter exhausts and the related appealing energy revenue was also recently discussed in [3] and [4]. Ozturk et al. [5] did an assessment of potential environmental benefits and

Corresponding author: daniele.fiaschi@unifi.it 
energy saving related to the application of 22 Best Available Techniques (BAT) to a cotton/polyester fabric finishing - dyeing textile mill. The application of these BAT revealed a significant potential in the reduction of the textile mill environmental and energy footprint. Cay [6] analyzed the energy consumption and saving potential in clothing industry, concluding that the specific energy consumption for manufacturing of one piece of knitted garment from dyed-finished fabric was in the range of $0.78-1.44 \mathrm{MJ} /$ piece, addressing potential energy savings of $16.4 \%$ for apparel, $14.4 \%$ for embroidery and $11.6 \%$ for screen printing plants. The presented short list of references shows the ever increasing interest in the last years towards better energy usage in textile industry. Nevertheless, much reduced amount of literature is available on sustainable and energy efficient fabric dry cleaning and almost nothing is found, neither at case study level, about the energy recovery potential in industrial laundry. In this field, the most frequent subject regards the comparison between wet and dry fabric cleaning and the issues on human health deriving from the use of perchloroethylene (PERC) in dry cleaning. Troynikov et al. [7] reviewed the state of the art and research evidence in the area of sustainable and safe apparel cleaning methods, addressing traditional ones using PERC as solvent, as well as those utilizing ecological solvents other than PERC, thus comparing their health hazards. In the same direction, Onasch [8] compared the wet and dry cleaning in a case study of professional garment care industry, concluding that an interesting economic save was possible converting the facilities from dry PERC cleaning to wet cleaning.

Anyhow, literature lacks of proposals, analysis and case studies regarding the potential of energy recovery and the related economic attractiveness of an industrial fabric dry laundry. Giving a contribution to fill this gap is the main focus of the present paper, which assess the low temperature waste heat recovery potential of an industrial fabric dry laundry located in Prato (Tuscany, Italy) and its conversion to electricity through an ORC, mainly directly re-used to satisfy the internal consumption of the laundry. The study also includes the economic analysis of the proposed solution.

\section{Outline of the dry laundry facilities and PERC solvent regeneration}

Dry cleaning is a typical process of the wool production chain aimed at removing dirt and all textile oils from both woven and knitted fabrics, using organic solvents. They solubilize fats and, thanks to their mechanical action, remove insoluble particles. The main used solvent is Tetrachlorethylene $\left(\mathrm{C}_{2} \mathrm{CI}_{4}\right)$ commonly known as PERC. Public opinion generally has the impression that washing with water has a much lower environmental impact than washing with solvents. Nevertheless, with nowadays technology, solvent vapour emissions can be reduced well below human and environmental hazard limits and, at the same time, concentrated residues can be properly managed and treated. The better ease of drying of solvents, compared to water, also allows a lower energy consumption and, therefore, a lower environmental impact. In fact, when washing in water, dirt and additives are discharged at each cycle, while when washing with solvents they are concentrated in the distiller and then disposed of and treated, recycling the solvent in the appropriate plants.

The solvent woven washing machine is a continuous machine where the fabric passes continuously inside in a linear and flat way, undergoing a washing treatment with PERC used as a solvent. The process is called dry cleaning. It consists of several steps:

- Washing, into counter-current baths operated by adjustable high pressure perchloroethylene pumps and final abatement of residual solvent in the fabric.

- Drying, with forced ventilation on the conveyor belt and drying chamber at $130{ }^{\circ} \mathrm{C}$.

- Deodorization, where the residual solvent odour on the fabric is removed from clean, properly recycled air in a closed circuit.

- Sludge distillation, composed of a dirty water-solvent separator, a primary and a secondary distiller. 
- Water treatment, where the water which has come into contact with the solvent is treated by a specific device to eliminate any solvent residues.

\section{Heat recovery potential from the process}

An accurate analysis of the machines and equipment of the dry cleaning plant under ordinary working conditions was carried out, in order to assess the heat recovery potential and the related temperature levels. The mill is equipped with a natural gas boiler and cogenerator. The following list summarizes the main sources of recoverable waste heat; the related data are taken from measurements on the components:

1) Natural gas boiler [9] with $1.53 \mathrm{~kg} / \mathrm{s}$ exhausts mass flow rate at $230{ }^{\circ} \mathrm{C}$;

2) Cogenerator for self-electricity production [10], with $0.583 \mathrm{~kg} / \mathrm{s}$ exhausts mass flow rate at $195^{\circ} \mathrm{C}$;

3) Four dry cleaning machines where two different heat sources, one from the distillation unit (condensation of solvent vapour) and the other from the drying unit (air). All the machines are equipped with PERC solvent distillation section, which is a recoverable waste heat source as well.

Table 1. Thermodynamic conditions of the waste heat flows of dry cleaning machinery

\begin{tabular}{|c|c|c|c|c|c|c|}
\hline \multicolumn{4}{|c|}{ Drying units } & \multicolumn{3}{c|}{ Distillation units } \\
\hline Unit nr. \# & $\begin{array}{c}\text { Temp. } \\
{[\mathbf{C}]}\end{array}$ & $\begin{array}{c}\text { Air flow } \\
\text { rate [kg/s] }\end{array}$ & $\begin{array}{c}\text { Condensed } \\
\text { solvent flow } \\
\text { rate [kg/s] }\end{array}$ & Unit nr. \# & $\begin{array}{c}\text { Temp. } \\
{[\mathbf{C}]}\end{array}$ & $\begin{array}{c}\text { Condensed } \\
\text { solvent flow } \\
\text { rate [kg/s] }\end{array}$ \\
\hline 1 & 130 & 59.6 & 0.135 & 1 & 121 & 0.316 \\
\hline 2 & 115 & 52.7 & 0.271 & 2 & 121 & 0.631 \\
\hline 3 & 130 & 79.4 & 0.203 & 3 & 121 & 0.473 \\
\hline 4 & 115 & 87.8 & 0.406 & 4 & 121 & 0.947 \\
\hline
\end{tabular}

Table 1 summarizes the flow rates and temperatures of the waste heat flows in the four dry cleaning machines units. The available waste heat is recovered into an Organic Rankine Cycle (ORC) for electricity generation only and not recycled within the production process because of two reasons: (1) the piping layout for collecting the whole waste heat into the ORC is much less complicated and invasive of the current production process; (2) the extra electricity generation with the ORC covers the current gap between the demand and the self produced amount with the cogenerator, in a context where the electricity price is relatively relevant. The ORC working condition and fluid were optimised in order to maximise the recovered heat, thus minimising the irreversibilities.

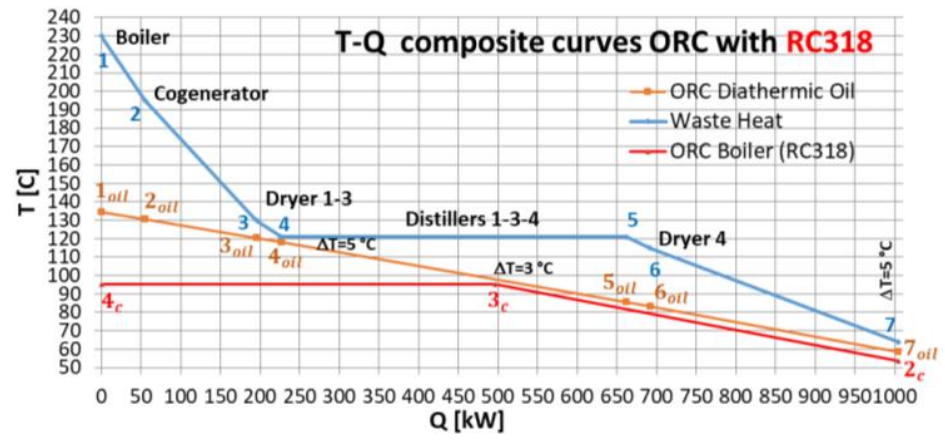

Fig. 1. Composite curves of waste heat - ORC energy recovery

The composite curves of the heat transfer from the wastes to the ORC through the diathermic oil are shown in Fig. 1. The overall heat recovered to the ORC is of about 1000 
$\mathrm{kW}$, with the largest share $(435 \mathrm{~kW})$ from the condensation of the PERC solvent into the distillers 1, 3 and 4. Dryer 2 and Distiller 2 are not working continuously; therefore, they have not been considered in the present analysis.

Table 2. Composite curves of waste heat - ORC energy recovery

\begin{tabular}{|c|c|c|c|c|c|c|c|}
\hline Point & $1 / 1_{\text {oil }}$ & $2 / 2_{\text {oil }}$ & $3 / 3_{\text {oil }}$ & $4 / 4_{\text {oil }}$ & $5 / 5_{\text {oil }}$ & $6 / 6_{\text {oil }}$ & $7 / 7_{\text {oil }}$ \\
\hline T waste heat [C] & 230 & 195 & 130 & 121 & 121 & 115 & 64 \\
\hline T oil [C] & 135 & 131 & 121 & 118 & 86 & 83 & 59 \\
\hline Q [kW] & 0 & 55 & 195 & 226 & 661 & 692 & 1004 \\
\hline
\end{tabular}

\section{Layout of the waste heat recovery pipeline and ORC}

In order to achieve the composite curves reported in Fig. 1, the layout of the waste heat recovery pipeline (shown in Fig. 2) was optimised towards the correct temperature matching between the waste heat providers and the boiler of the ORC. Moreover, the constraints present within the premises were taken into account in the heat recovery layout, trying to minimize the invasiveness of the installation. The ORC and pipeline of the heat recovery system, as well as the composite curves of Fig. 1, were simulated with well tested in house codes of the research group, developed in EES environment.

Four organic fluids were analysed in the simulation of the ORC: R1234yf, R245fa, Propane and RC318 (Table 3). The latter was selected due to the best cycle performance, allowing the conversion of the waste heat into $92.5 \mathrm{~kW}$ electricity, at $9.23 \%$ efficiency. The related power cycle and working conditions are shown on Fig. 3 and table 3 respectively.

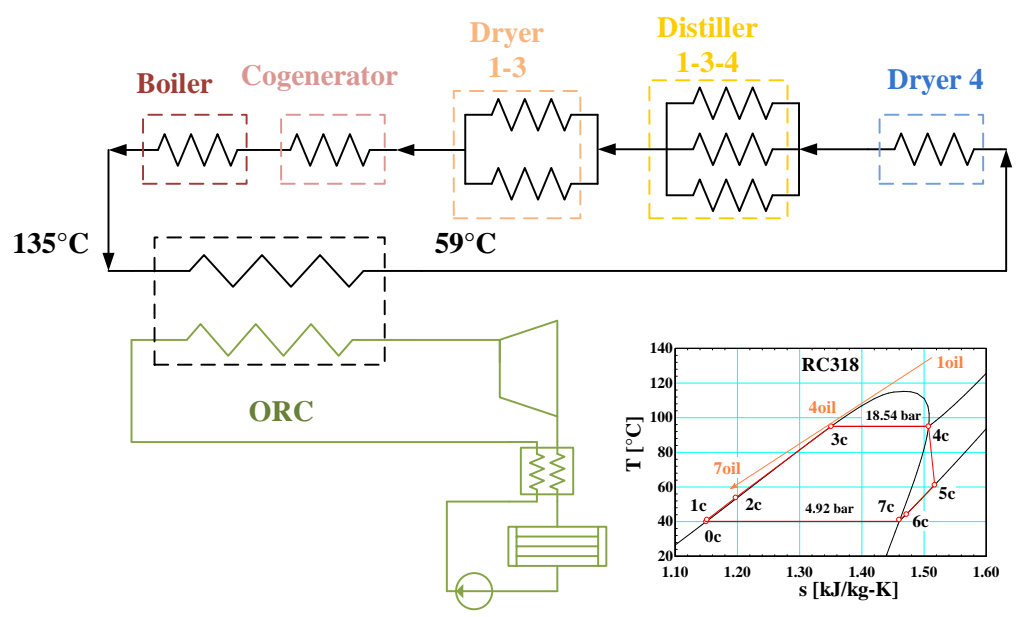

Fig. 2. Layout of the waste heat recovery and T-s diagram of the ORC cycle

Table 3. ORC data and recovered waste heat: performance comparison of different fluids

\begin{tabular}{|r|c|c|c|c|}
\hline \multicolumn{1}{|c|}{ ORC Fluid } & RC318 & R1234yf & R245fa & Propane \\
\hline Maximum cycle temperature $\mathrm{T}_{4}[\mathrm{C}]$ & 95 & 94,5 & 55 & 93 \\
\hline Condenser temperature $\mathrm{T}_{0}[\mathrm{C}]$ & 40 & 40 & 40 & 40 \\
\hline Maximum cycle pressure $\mathrm{P}_{4}[\mathrm{bar}]$ & 18.5 & 33,7 & 4 & 39,7 \\
\hline Condenser pressure $\mathrm{P}_{0}[\mathrm{bar}]$ & 4.92 & 10,2 & 2,5 & 13,7 \\
\hline ORC flow rate $[\mathrm{kg} / \mathrm{s}]$ & 9.04 & 8,4 & 5,7 & 3,5 \\
\hline Pump power $[\mathrm{kW}]$ & 12.2 & 27,2 & 0,9 & 27,9 \\
\hline ORC efficiency [\%] & 9.23 & 5.86 & 3.40 & 6.71 \\
\hline ORC power output [kW] & 92.5 & 67.3 & 36.6 & 75.9 \\
\hline Total recovered waste heat $[\mathrm{kW}]$ & 1004 & 1004 & 1004 & 1004 \\
\hline Waste heat to ORC economizer $[\mathrm{kW}]$ & 483 & 878 & 97 & 630 \\
\hline
\end{tabular}




\section{Energy and economic analysis}

The electricity produced by the ORC, which converts the waste heat from the dry cleaning machinery and the existing plants of the analysed laundry, is utilized internally, in order to satisfy the electricity needs of the mill. The yearly average working hours of the company are about 2600 (about 8 working hours/day, holidays and weekend included). It is reasonable to consider that the ORC works following the working time of the laundry, because it exploits the waste heat of the related processes and plants. With this production, the waste heat converted into electricity by the ORC covers almost the currently purchased electricity from the network, leaving only very small gaps in January and April (Fig. 3). It shows the worthiness of converting the laundry waste heat into electricity, which also suits the circular economy of the company.

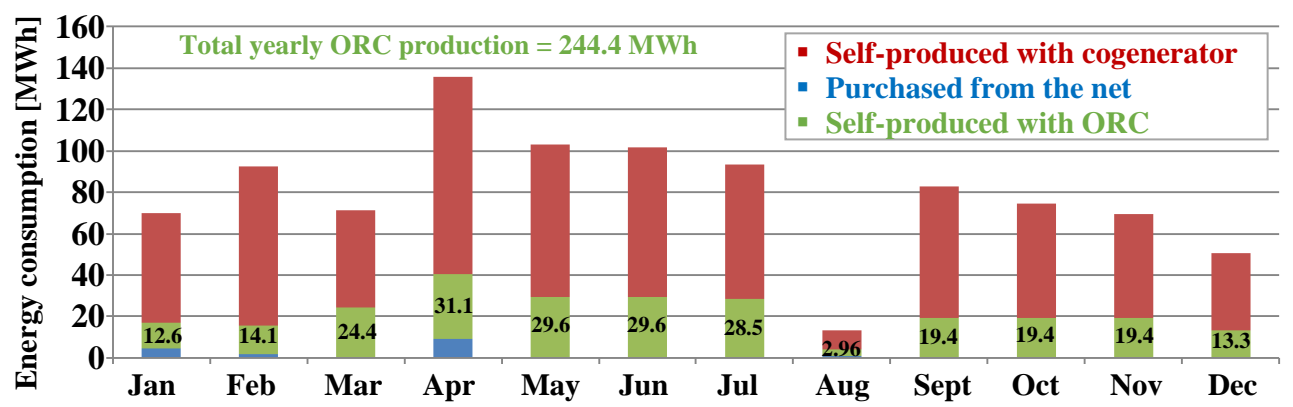

Fig. 3. Electricity consumption of the laundry including the net/cogenerator/ORC share

The economic analysis of the waste heat recovery system was based on the assumption that the whole electricity and heat produced by the co-generator and the waste heat recovery ORC are self-consumed into the mill. So, the yearly revenue for the company was calculated in terms of saves from network electricity purchase. In this way, as the ORC works timely in phase with the machinery and plants of the industrial laundry, from the data available on Fig. 4 the electricity saves are easily accountable. To do this, an average cost of industrial electricity of $15 \mathrm{c} €$ (tax inclusive, [11]) was considered for the yearly consumption range of the company $(500-2,000 \mathrm{MWh})$. The yearly electricity save for self-production is about $36,650 €$, coming from $244 \mathrm{MWh}$ produced. Moreover, the waste heat recovery is entitled to Energy Efficiency Titles (EET e.g. White Certificates), which may be estimated at about $250 € /$ tep primary energy in Italy [12]. Considering that one tep corresponds to $5,347 \mathrm{kWh}$ electricity, the yearly income from EET for the produced electricity from waste heat $(244.4 \mathrm{kWh} /$ year $)$ is about $11,420 €$. The overall investment cost for the waste heat recovery system, including the ORC, pipeline and heat exchangers, was assumed at about 3,750 €/kW for the $92.5 \mathrm{~kW}$ here considered (table 3), which is in line with literature values $[13,14]$. Considering the yearly electricity saves and the incomes for EET, the simple Payback Time of the investment (PBT) is about 7 years referring to a reasonable 20 years' lifetime. It is rather attractive, also considering that this result is conservative, as some other contributions were not included like, for example, the super depreciation premium on the $140 \%$ of capital cost, which is currently acknowledged by the Italian government for investments aimed to improve the energy efficiency in industrial activities.

\section{Conclusions}

The objective of the current work was the assessment of waste heat recovery and its conversion to electricity, applied to a fabric dry cleaning industrial process. Different waste heat flows were selected and characterized, in order to assess their overall potential, which 
was estimated at about $1000 \mathrm{~kW}$ during the working time. The design of the plant layout for catching the waste heat flows and convey them to the ORC power plant for the conversion to electricity was carried out, taking care of the correct matching of the waste heat - boiler heat transfer composite curves, in order to maximise the conversion of the recovered heat to electricity, while minimizing the irreversibilities. To do this, the ORC was optimized, selecting RC318 as the most suitable working fluid in a $92.5 \mathrm{~kW}$ power cycle. The seasonal electricity produced by the ORC matched very well the current existing gaps between the self-production from the existing co-generator and the company's internal demand. For this reason, it resulted very attractive for the proposed application.

Finally, an economic analysis of the proposal was carried out, considering realistically referred capital costs, electricity price and value of Energy Efficiency Titles: it revealed an interesting 7 years PBT, even though calculated with conservative assumptions on further tax benefits, that were not considered and may allow additional significant reduction.

\section{References}

[1] A. Hasanbeigi, L. Price, A review of energy use and energy efficiency technologies for the textile industry, Renew. Sust. Energ. Rev. 16 (2012) 3648- 3665.

[2] M.I. Rakib, R. Saidur, E.N. Mohamad, A.M. Afifi, Waste-heat utilization - The sustainable technologies to minimize energy consumption in Bangladesh textile sector, J. Clean. Prod. 142 (2017) 1867 - 1876.

[3] D. Fiaschi, G. Manfrida, L. Russo, L. Talluri, Improvement of waste heat recuperation on an industrial textile dryer: Redesign of heat exchangers network and components, Energy Conver. Manag. 150 (2017) 924-940.

[4] L. Ciappi, D. Fiaschi, G. Manfrida, S. Salvadori, J. Smolka, L. Talluri, Heat Recovery for a Textile Stenter: CFD Analysis of Air Curtain Benefits, Energies 2019, 12, 482.

[5] E. Ozturk, H. Koseoglu, M. Karaboyaci, N.O. Yigit, U. Yetis, M. Kitis, Sustainable textile production: cleaner production assessment/eco-efficiency analysis study in a textile mill, J. Clean. Prod. 138 (2016) 248 - 263.

[6] A. Çay, Energy consumption and energy saving potential in clothing industry, Energy 159 (2018) $74-85$.

[7] O. Troynikov, C. Watson, A. Jadhav, N. Nawaz, R. Kettlewell, Towards sustainable and safe apparel cleaning methods: A review, J. Environ. Manage. (2016) 252 - 264.

[8] J. Onasch, A feasibility and cost comparison of perchloroethylene dry cleaning to professional wet cleaning: case study of Silver Hanger Cleaners, Bellingham, Massachusetts, J. Clean. Prod. 19 (2011) 477 - 482.

[9] Mingazzini steam boilers, http://www.mingazzini.com/webproduct eng.php?cid=57

[10] Enerblu Cogeneration http://www.enerblu-cogeneration.com/en/product models/313rec2-400-g

[11] EUROSTAT Statistics explained/index.php?title=File:

Electricity_prices_for_industrial_consumers, second_half_2015_(\%C2\%B9)_(EUR per kWh) YB16.png

[12] GME (Gestore Mercati Energetici), Relazione Annuale 2017, https://www.mercatoelettrico.org/it/MenuBiblioteca/documenti/20180723BilancioRel azione2017.pdf, in Italian.

[13] S. Quoilin, S. Declaye, B.F. Tchanche, V. Lemort, (2011). Thermo-economic optimization of waste heat recovery Organic Rankine Cycles. Appl. Therm. Eng., 31(14), 2885-2893.

[14] M. Imran, B.S. Park, H.J. Kim, D.H. Lee, M. Usman, \& M. Heo, (2014). Thermoeconomic optimization of Regenerative Organic Rankine Cycle for waste heat recovery applications. Energy Conver. Manag. , 87, 107-118. 